\title{
Retraction Note: Soybean processing wastewater supported the removal of propyzamide and biochemical accumulation from wastewater by Rhodopseudomonas capsulata
}

\author{
Pan $\mathrm{Wu}^{1,2} \cdot$ Ziqiao $\mathrm{Han}^{1} \cdot$ Wentao $\mathrm{Mo}^{1} \cdot$ Xiaozhen $\mathrm{Wu}^{1} \cdot$ Zhaobo $\mathrm{Chen}^{1,2} \cdot$ Ying Zhang $^{1,2} \cdot$ Yanling Wang ${ }^{3} \cdot$ \\ Yubo Cui ${ }^{1}$. Yuying Dong ${ }^{1,2} \cdot$ Hongjie Sun $^{1,2} \cdot$ Xuejun Zou ${ }^{1,2}$
}

Published online: 27 March 2021

(c) Springer-Verlag GmbH Germany, part of Springer Nature 2021

\section{Retraction to: Bioprocess and Biosystems Engineering (2019) 42:1375-1384 \\ https://doi.org/10.1007/s00449-019-02137-2}

The Editor-in-Chief has retracted this article because it significantly overlaps with previously published articles [1,2], which were submitted and published within a close time frame. Co-author Pan Wu has informed us that he is the sole author responsible for this submission and included the other listed co-authors without their knowledge or consent. Co-authors Pan $\mathrm{Wu}$, Zhaobo Chen and Ying Zhang agree with this retraction, but have not responded to correspondence regarding this retraction notice. Co-authors Ziqiao Han, Wentao Mo, Xiaozhen Wu, Yanling Wang, Yubo Cui, Yuying Dong, Hongjie Sun and Xuejun Zou could not be reached for comment on this retraction.

\section{References}

1. Pan Wu, Chen Z, Zhang Y, Wang Y, Zhu F, Cao Bo, Yuan Wu, Li N (2019) Rhodopseudomonas palustris wastewater treatment: Cyhalofop-butyl removal, biochemicals production and mathematical model establishment. Biores Technol 282:390-397. https:// doi.org/10.1016/j.biortech.2018.11.087

2. Wu P, Shi J, Zhang Y et al (2019) The bioremediation of metolachlor in soil using Rhodospirillum rubrum after wastewater treatment. J Soils Sediments 19:3534-3544. https://doi.org/10.1007/ s11368-019-02279-6

Publisher's Note Springer Nature remains neutral with regard to jurisdictional claims in published maps and institutional affiliations.
The original article can be found online at https://doi.org/10.1007/ s00449-019-02137-2.

\section{Zhaobo Chen}

13587568799@163.com

Ying Zhang

13715187294@163.com

1 School of Environment and Resources, Dalian Minzu University, Dalian 116600, China

2 School of Resources and Environment, Northeast Agricultural University, Harbin 150030, China

3 Department of Anesthesiology, The Third Affiliated Hospital of Sun Yat-Sen University, Guangzhou 510630, China 